\title{
Comparative Desensitizing Effect of a Toothpaste \& Mouthwash- Containing Potassium Nitrate: An In Vivo \& In Vitro Scanning Electron Microscopic Study
}

\author{
Siladitya Sen*, K Meena Ananad and Pratibha P k \\ Department of Periodontology, Manipal College of Dental Sciences, India
}

Submission: October 25, 2017; Published: May 21, 2018

*Corresponding author: Siladitya Sen, Department of Periodontology, Manipal College of Dental Sciences, Manipal, India, Email: dr.sen02@yahoo.com

\section{Abstract}

Potassium Nitrate has been used as a desensitizing agent to treat dentinal hypersensitivity for quite a long time. The effectiveness of a potassium nitrate is evaluated many times in the form of toothpaste. There hasn't been much study done to evaluate the desensitizing efficacy of potassium nitrate used in the form of mouthwash. Aim of our study was to compare the desensitizing effect of a tooth paste \& mouthwash-both containing Potassium Nitrate.

Material \& Methods: Thirty patients were assessed using evaporative stimuli and thermal stimuli and tactile stimuli and response was evaluated using Visual Analogue Scale at baseline and after 1 month. The patients were divided into two groups; Group I: fifteen patients who used toothpaste containing 5\% potassium nitrate, sodium fluoride, xylitol; Group II: Fifteen patients who used mouthwash containing $3 \%$ potassium nitrate, sodium fluoride, xylitol. A total of ten extracted human teeth were collected. Horizontal ground section was done in all the teeth. In five ground section of teeth potassium nitrate containing tooth paste were applied and in five ground sections were shaken vigorously in potassium nitrate mouth rinse. All the ground sections were taken for scanning electron microscopic evaluation.

Result: The results of all the stimulus assessment methods indicated that potassium nitrate toothpaste as well as mouthwash showed statistically significant decrease in the sensitivity score on a Visual Analogue Scale compare to baseline. But, there were no statistically significant differences between the groups, although both were effective in the treatment of hypersensitivity toothpaste showed slightly better result. Scanning electron microscopic analysis result showed that there were partial to complete occlusion of dentinal tubules in toothpaste group. However, no such tubule occlusion effect found in mouthwash group.

Conclusion: Both toothpaste and mouthwash containing potassium nitrate are effective in reducing dentinal hypersensitivity. However toothpaste was having slightly better result.

\section{Introduction}

Dentinal hypersensitivity is a clinical condition originating from exposure of dentinal tissue and characterized by painful sensation after thermal, chemical, mechanical or osmotic stimuli. Clinically it is perceived as an acute, localized, rapidly developing and short duration pain [1]. This painful clinical condition affects $8 \%$ to $35 \%$ of the population [2]. The incidence of Dentinal Hypersensitivity (DH) reportedly peaks during the third and fourth decades of life [3].

There are many varied etiologic and predisposing factors related to DH. Removal of enamel, as a result of attrition, abrasion, and erosion, or denudation of the root surface by overlying cementum and periodontal tissue loss, are commonly cited [4]. Exposure of the root surface area may be multifactorial, chronic trauma from tooth brushing, tooth flexure caused by abnormal occlusal loading forces, parafunctional habits, acute and chronic inflammatory gingival and periodontal diseases, acute trauma, periodontal surgery, and acidic dietary components are commonly cited as major causes of cervical lesions and DH [5].

Pain caused by DH can be explained by the widely accepted "hydrodynamic theory" proposed by Braennstroem \& Astroem in 1964 [6]. According to this theory, the presence of lesions involving enamel or cementum loss in cervical areas and the consequent opening of dentinal

tubules to the oral environment, under certain stimuli, allow the movement of dentinal fluid inside the tubules, indirectly stimulating the extremities of the pulp nerves, causing the pain sensation. It is also found that open dentinal tubules serve as pathways for diffusive transport of bacterial elements in the oral cavity to the pulp, which may cause a localized inflammatory pulpal response [7]. Histologically, under transmission electron 
microscope, a sensitive tooth shows widened dentinal tubules, two times larger than tubules of normal dentin and in greater number per area compared to a tooth without DH [8]. Although macroscopically the dentin of a hypersensitive tooth does not differ from that of a normal tooth, the symptoms suggest minorinflammation of pulp [9].

Various strategies have been implicated in the treatment of $\mathrm{DH}$, including lasers, ions and salts, fluoride iontophoresis, dentin sealers, periodontal soft tissue grafting, and homeopathic medications [10]. It is still not possible, however, to reach a consensus about which techniques represent the gold standard in the treatment of DH.

Currently, two main approaches are used in the treatment and prevention of DH: tubular occlusion and blockage of nerve activity. In the tubular occlusion approach, the tooth is treated with a physical or chemical agent that forms a layer that mechanically occludes the dentinal tubules and prevents pulpal fluid flow, thereby leading to reduction in DH $[11,12]$. Such treatment strategies as lasers, dentin sealers, and periodontal soft tissue grafting work on the same principle. In blockage of nerve activity, potassium ion tends to concentrate in the interior of the dentinal tubules, causing a depolarization of the cellular membrane of the nerve terminal and a refractory period with decreased sensitivity [13]. Dentifrices containing potassium ions have been shown by several clinical studies to be effective in reducing dentine hypersensitivity and the American Dental Association Council on Dental Therapeutics has granted a Seal of Acceptance to dentifrices containing $5 \%$ potassium nitrate (Council on Dental Therapeutics 1986)

Potassium nitrate is used either as a toothpaste as or as a mouthwash. And, there is always a confusion regarding whether it is effective when delivered as toothpaste or as a mouthwash. There has been evidence in literature which shows that both the formulations have therapeutic potential to alleviate dentinal hypersensitivity $[14,15]$. But, the studies which compare the effectiveness of toothpaste and a mouthwash are few in number. The present study is designed to compare the effectiveness of desensitizing toothpaste and a mouthwash, both containing potassium nitrate for the treatment of dentinal hypersensitivity.

\section{Material and Methods}

The present study was a randomized clinical trial conducted in Department of Periodontics (Manipal college of Dental Sciences, Manipal). Thirty patients were recruited forthe study. Inclusion criterion was, patients reporting with sensitivity in teeth for hot, cold, sweet, or sour food / beverages. Exclusion criteriawas -Subjects with history of treatment for dentin hypersensitivity, poor periodontal condition, systemic debilitating disease, caries or restoration in the area of hypersensitivity, allergy to the agents used in the study, patients with orthodontic appliance, crowns. In the first visit, oral prophylaxis was given to every patient. Severity of dentinal hypersensitivity measured, by three different types of stimulus tests. a) Sensitive teeth identified first by tactile method- pulling a single scratch / stroke by a sharp explorer at the cervical region of teeth. (Figure 1) Subjects will be asked to rate the subjective perception of the sensitivity during scratch process as a score of 0 to 10 (where $0=$ no pain and $10=$ unbearable pain) based on the visual analog scale (VAS) The VAS was a $10-\mathrm{cm}$ line with the anchor words "no pain" $(0 \mathrm{~cm})$ and "intolerable pain $(10 \mathrm{~cm})$ " at the opposite ends.

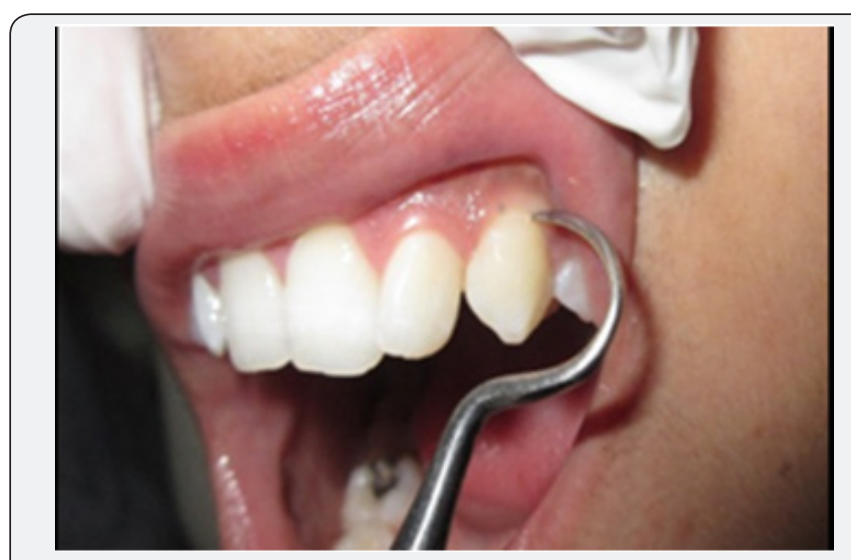

Figure 1: Tactile test with a help of a sharp explorer.

b) Each participant was asked to place a vertical mark on the VAS to indicate the intensity of his or her level of sensitivity after receiving stimuli.

c) Exactly after 10 minutes after the tactile test-Exposing each teeth to air using ( 2 way syringe) dental air syringe at 30 psi pressure and $23+/-3^{\circ} \mathrm{c}$ temperature for $1 \mathrm{sec}$. Syringe kept $1 \mathrm{~cm}$ from the tooth and held perpendicularly for 2 seconds. (Figure 2) After the test subjects asked to rate the subjective perception of the sensitivity during scratch process as a score of 0 to 10 ( where $0=$ no pain and $10=$ unbearable pain)

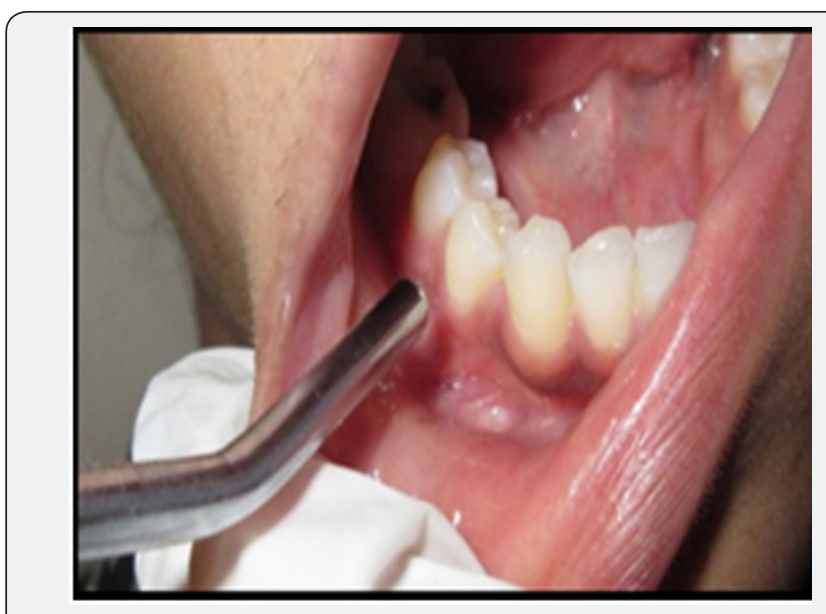

Figure 2: Air blast test with the help of a two way dental syringe

d) Five minutes after air blast test freezed cold water applied to sensitive tooth with help of a disposable syringe for 2 seconds. (Figure 3) Patient's perception again was recorded in VAS score values. 


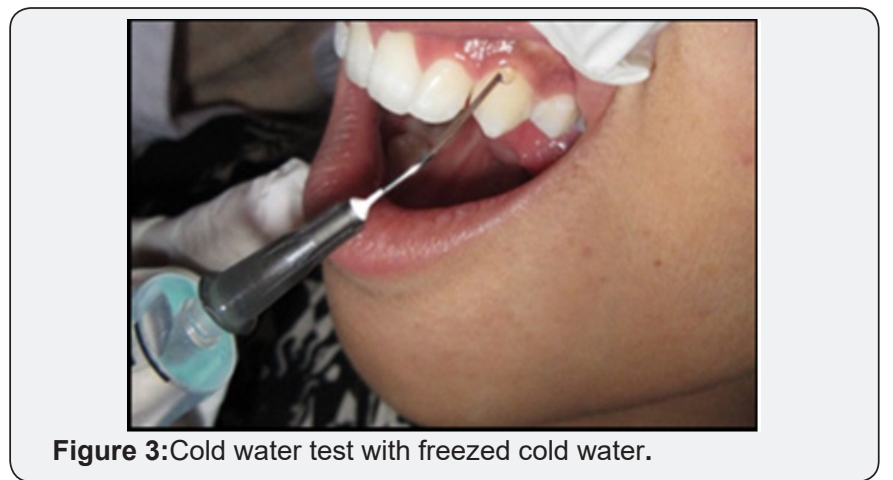

After conducting three stimulus test all the 30 patients were randomly divided in to two groups. Group-A: received desensitizing toothpaste and Group-B: received desensitizing mouthwash. Randomization was done by asking patients to pick up a chit of a paper written either tooth paste or mouthwash. Then all the patients in both groups undergone through periodontal examination like bleeding on probing, probing pocket depth and gingival recession. Ultrasonic scaling given to all the patients in both group. A common instruction given all patients in both group that they should use a soft tooth brush and brush in rolling type of brushing method twice daily for 3 minutes. One additional instruction given to the patients belong to the mouthwash group that they should use same old toothpaste and not to use any desensitizing toothpaste and thirty minutes after brushing they should take $10 \mathrm{ml}$. of desensitizing mouthwash and rinse mouth for 1 minutes and then spit out.

All the patients were recalled exactly after one month and same three stimulus tests were again carried out and patient's perception were recorded in VAS score.

\section{In-vitro study}

Ten extracted human teeth were collected from department of maxillofacial surgery. One millimeter thickness horizontal ground sections were made with the help of coarse diamond grit and straight micromotor hand piece. (Figure $4 \& 5$ ) In five horizontal tooth section potassium nitrate tooth paste was applied with the help of paint brush and rest of the five horizontal tooth section were taken in container filled with potassium nitrate mouthwash and shaken vigorously to simulate the natural mouth rinsing action. Then, all the ten horizontal tooth sections were taken for Scanning Electron Microscopic (SEM) analysis.

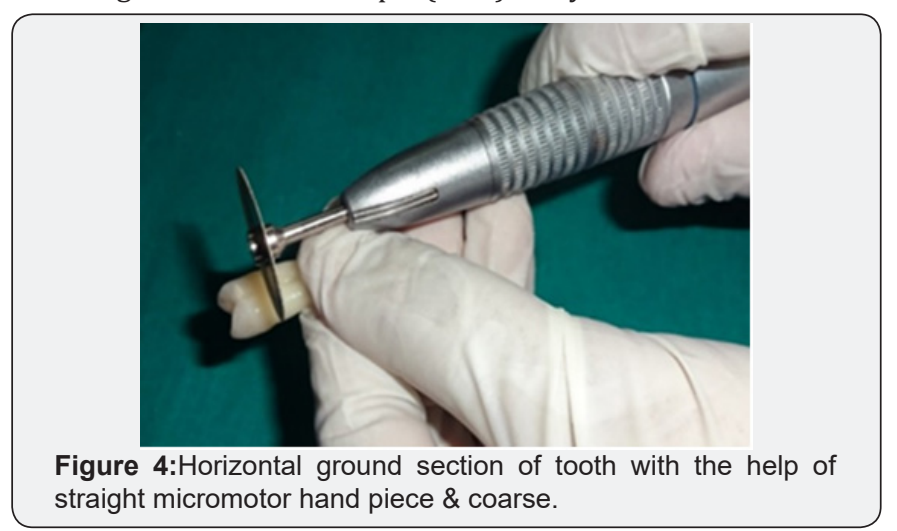

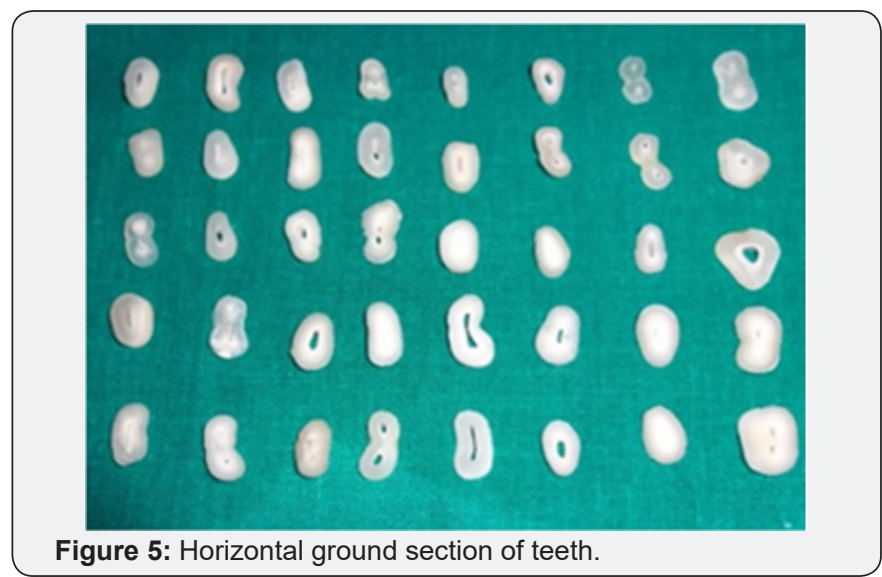

\section{Statistical Analysis}

In the present study, descriptive statistics are presented as Mean \pm Standard Deviation (SD) based on the 10 -cm Visual Analogue Scale (VAS). Students paired' $t$ ' test was used to compare the intergroup variation and independent sample ' $t$ ' test used to make intergroup variation. Calculations were performed using the statistical package SPSS (Statistical Program for Social Sciences) version 16 (SPSS Inc, chigaco) and $\mathrm{p}<0.05$ was considered to be significant.

\section{Results}

28 out of 30 patients completed the study after one month. Unfortunately two patients belong to mouthwash group did not for follow up evaluation. There was no incidence of any adverse reaction to any of the agents used in the study. Result of intergroup analysis (with the help of independent sample ' $t$ ' test) showed that there was no statistical significant difference at the base line as well as after one month follow up (except with respect to tactile test toothpaste group showed statistical significant reduction of VAS score compared to mouthwash group) between two groups with respect to any of the parameters used in the study (like tactile, air blast, cold water test or bleeding on probing, pocket depth, gingival recession) (Table 1).

Table 1: Inter group analysis with the help of independent sample ' $t$ ' test.

\begin{tabular}{|c|c|c|c|c|c|c|}
\hline & & \multicolumn{4}{|c|}{ Group } & \multirow{3}{*}{ p-value } \\
\hline & & \multicolumn{2}{|c|}{ A (Toothpaste) } & \multicolumn{2}{|c|}{ B(Mouthwash) } & \\
\hline & & Mean & SD & Mean & SD & \\
\hline \multirow{6}{*}{ Baseline } & Tactile & 1.4 & 0.51 & 1.54 & 0.52 & 0.482 \\
\hline & Air & 3.8 & 0.41 & 3.85 & 0.55 & 0.803 \\
\hline & Cold & 2.93 & 0.7 & 2.62 & 0.65 & 0.228 \\
\hline & BOP & 10.27 & 2.19 & 9.15 & 2.67 & 0.236 \\
\hline & PPD & 3.6 & 1.45 & 2.92 & 1.26 & 0.202 \\
\hline & CAL & 0.97 & 0.97 & 0.73 & 0.75 & 0.477 \\
\hline \multirow{4}{*}{$\begin{array}{l}\text { Follow- } \\
\text { up }\end{array}$} & Tactile & 0.93 & 0.46 & 1.31 & 0.48 & $\begin{array}{c}0.045 \\
\text { Sig }\end{array}$ \\
\hline & Air & 1.87 & 0.83 & 2.31 & 0.75 & 0.156 \\
\hline & Cold & 1.73 & 0.8 & 2 & 0.58 & 0.317 \\
\hline & BOP & 2.53 & 1.13 & 2.54 & 1.51 & 0.992 \\
\hline
\end{tabular}




\section{Advances in Dentistry \& Oral Health}

\begin{tabular}{|c|c|c|c|c|c|c|}
\hline \multirow{2}{*}{} & PPD & 2.27 & 1 & 1.69 & 0.63 & 0.077 \\
\cline { 2 - 7 } & CAL & 0.97 & 0.97 & 0.73 & 0.75 & 0.477 \\
\hline
\end{tabular}

However, result of intra group analysis (with the help of paired ' $\mathrm{t}$ ' test) showed that both toothpaste and mouthwash making significant reduction of VAS score in follow up visit compare to baseline visit (Table 2).

Table 2: Intra group analysis with the help of paired 't' test.

\begin{tabular}{|c|c|c|c|c|c|c|}
\hline \multirow{2}{*}{ Group } & & \multicolumn{2}{|c|}{ Baseline } & \multicolumn{2}{c|}{ Follow-up } & \multirow{2}{*}{ p-value } \\
\cline { 3 - 7 } & Mean & SD & Mean & SD & \\
\hline \multirow{4}{*}{$\begin{array}{c}\text { A } \\
\text { (Toothpaste) }\end{array}$} & Tactile & 1.4 & 0.51 & 0.93 & 0.46 & $\begin{array}{c}0.004 ; \\
\text { Sig }\end{array}$ \\
\cline { 2 - 7 } & Air & 3.8 & 0.41 & 1.87 & 0.83 & $\begin{array}{c}<0.001 ; \\
\text { Sig }\end{array}$ \\
\cline { 2 - 7 } & Cold & 2.93 & 0.7 & 1.73 & 0.8 & $\begin{array}{c}<0.001 ; \\
\text { Sig }\end{array}$ \\
\hline \multirow{2}{*}{$\begin{array}{c}\text { B } \\
\text { (Mouthwash) }\end{array}$} & Tactile & 1.54 & 0.52 & 1.31 & 0.48 & 0.082 \\
\cline { 2 - 7 } & Air & 3.85 & 0.55 & 2.31 & 0.75 & $\begin{array}{c}<0.001 ; \\
\text { Sig }\end{array}$ \\
\cline { 2 - 6 } & Cold & 2.62 & 0.65 & 2 & 0.58 & $\begin{array}{c}<0.001 ; \\
\text { Sig }\end{array}$ \\
\hline
\end{tabular}

Table 3: independent sample ' $t$ ' test.

\begin{tabular}{|c|c|c|c|c|c|}
\hline \multirow{2}{*}{ Difference } & \multicolumn{4}{|c|}{ Group } & \multirow{2}{*}{ p-value } \\
\cline { 2 - 5 } & \multicolumn{2}{|c|}{ A (Toothpaste) } & \multicolumn{2}{|c|}{ B (Mouthwash) } & \\
\cline { 2 - 5 } & Mean & SD & Mean & SD & \\
\hline Tactile & 0.47 & 0.52 & 0.23 & 0.44 & $0.208 ;$ NS \\
\hline Air & 1.93 & 0.96 & 1.54 & 0.78 & $0.247 ;$ NS \\
\hline Cold & 1.2 & 0.86 & 0.62 & 0.51 & $0.042 ;$ Sig \\
\hline
\end{tabular}

In order to find out which one more efficacious toothpaste or mouthwash we use independent sample ' $t$ ' test and we found with respect to tactile and air blast test toothpaste showed greater reduction of follow up VAS score compare to baseline VAS score ; however this difference found to be not statistically significant. But with respect to cold water test toothpaste showed statistically significant reduction of follow up VAS score compare to baseline VAS score. In overall with respect all three different stimulus test toothpaste showed slightly better result than mouthwash (Table 3 \& Figure 6). SEM analysis showed that tooth paste containing potassium nitrate causing partial to complete occlusion of dentinal tubules, whereas mouth wash group did not showed any kind tubular occlusion effect (Figure 7-10).

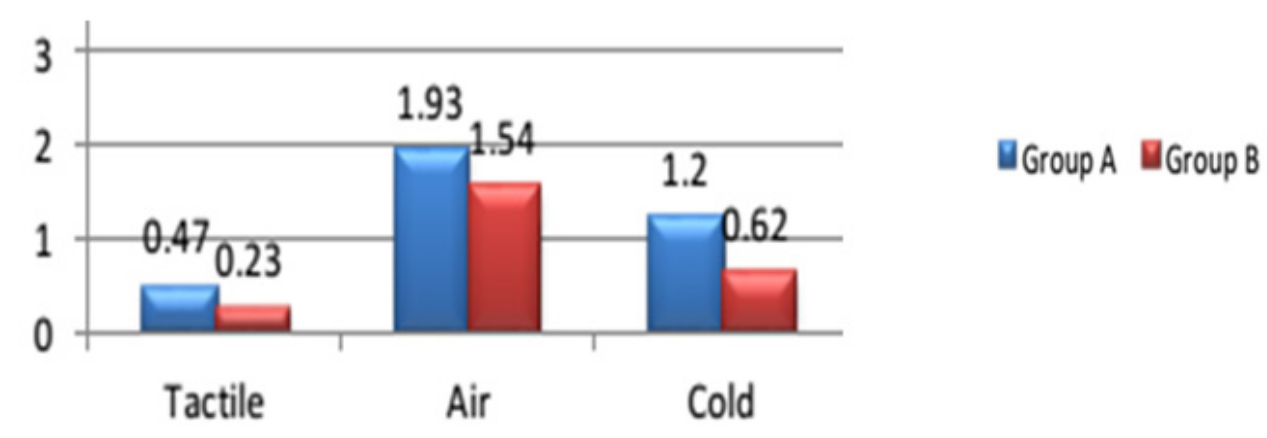

Figure 6

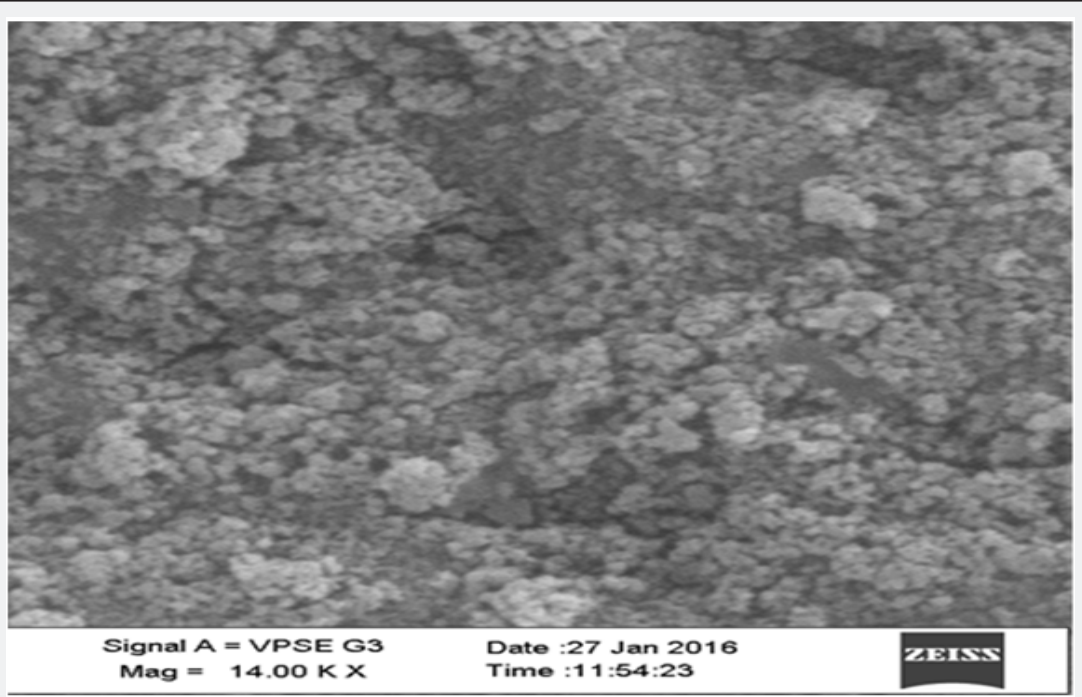

Figure 7: SEM picture of tooth specimen containing tooth paste showing all dentinal are occluded. 


\section{Advances in Dentistry \& Oral Health}

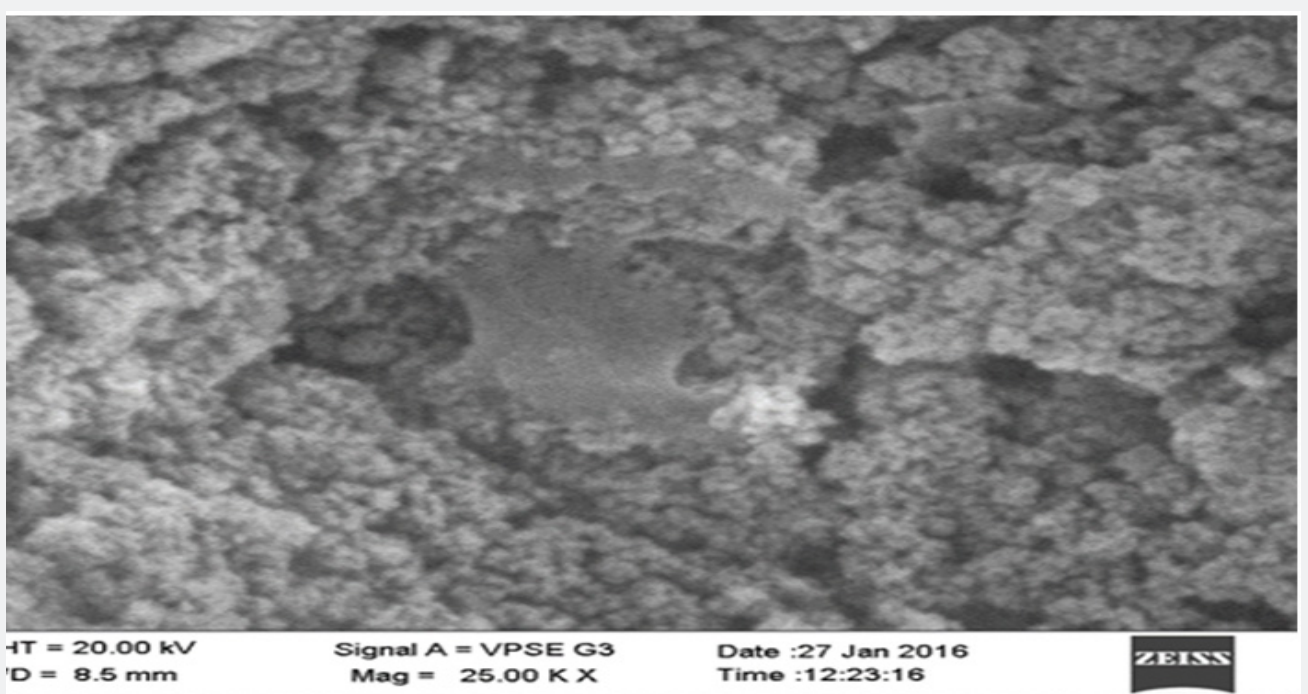

Figure 8:SEM picture of tooth specimen containing tooth paste showing a dentinal are occluded in higher magnification.

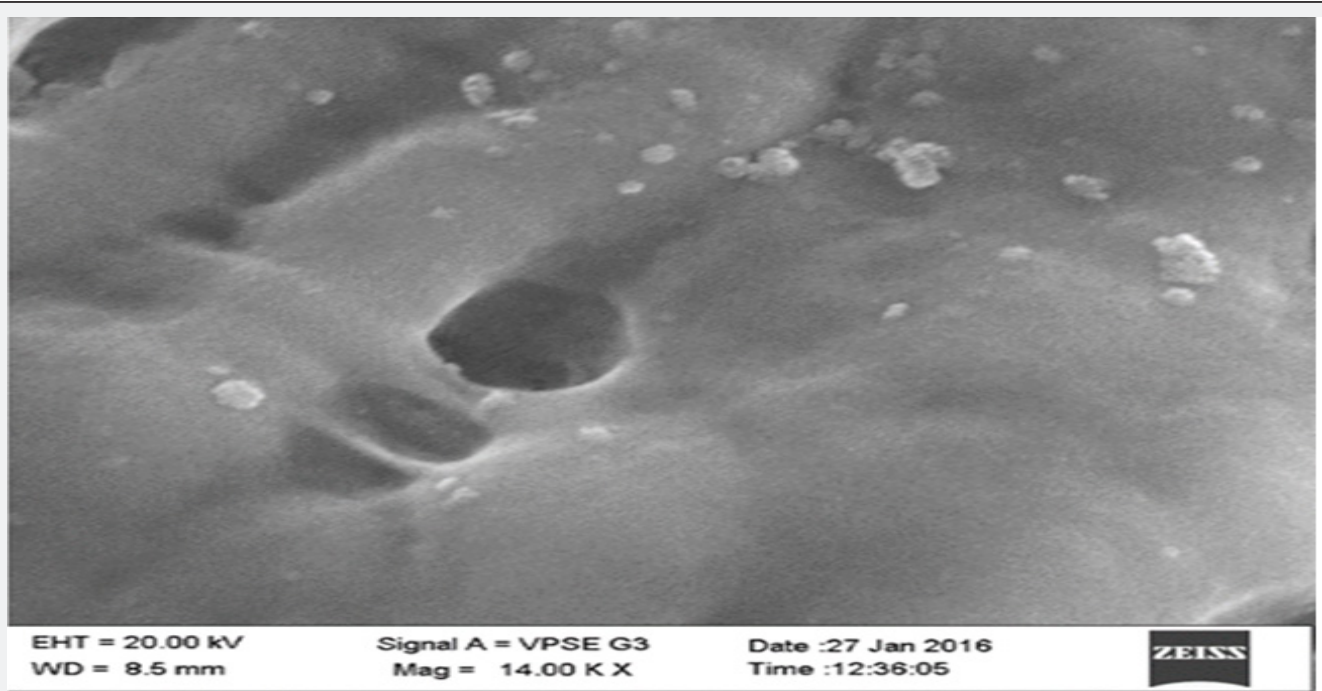

Figure 9:SEM picture of Mouthwash tooth sample in higher magnification, all tubules are open.

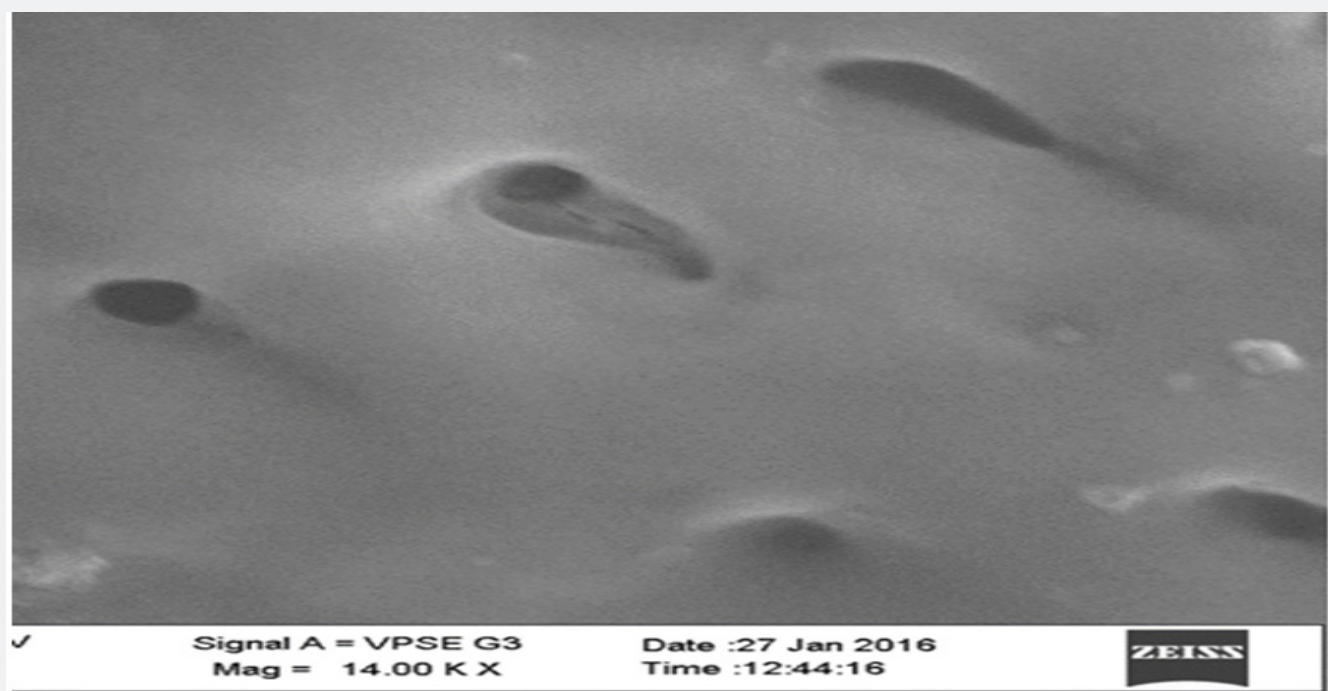

Figure 10:SEM picture of Mouthwash tooth sample in lower magnification, all tubules are open. 


\section{Discussion}

The present study was a randomized clinical trial to evaluate and compare the efficacy of toothpaste containing 5\% potassium nitrate, sodium fluoride, xylitol and a mouthwash containing $3 \%$ potassium nitrate, sodium fluoride in the treatment of dentinal hypersensitivity.

The results of the study showed that both desensitizing toothpaste and mouthwash are effective in reducing sensitivity within one month evaluation period, despite the different application procedure. Previous studies have reported that dentifrices containing potassium ions are effective in reducing sensitivity [16,17] and the American Dental Association Council on Dental Therapeuticshas granted its Seal of Acceptance to dentifrices containing $5 \%$ potassium nitrate [18].

The subjective nature of DH pain makes objective evaluation of it difficult. In the present study, we found that both mouthwash and toothpaste were effective in reducing $\mathrm{DH}$, as indicated by reduction of VAS scores. To determine the participants' sensitivity levels in the study, we translated the subjective perception to tactile, air blast and thermal (cold water) stimuli into objective data using VAS, which is the most appropriate method to use to diagnose pain levels [19]. To assess pain, we used more than one stimulus as recommended by Holland et al. [20].

Patients were advised to use soft tooth brush. Use of hard tooth brush many times leads to formation of cervical abrasion; which ultimately leads to dentinal hypersensitivity. Studies have shown that use of soft tooth brush exerts less pressure and reduces the incidence of gingival laceration or cervical abrasion [21,22]. Patients were advised to follow rolling brush technique. Faulty brushing technique always causes more incidence of cervical abrasion. Studies have shown that rolling technique is easier for the patients to learn and has almost equal effectiveness in tooth cleaning $[23,24]$.

In the present study desensitizing toothpaste containing potassium nitrate showed slightly better result than mouthwash containing potassium nitrate. It can be explained by result of the study done by Addy et al. [25] and Masant Kuroiwa et al. [26]; which showed that brushing always has a smearing action, pushing smear layers within the dentinal tubules and occluding them and making them less sensitive to stimulus. As it was proven by our SEM analysis, which clearly showed that in the tooth samples containing potassium nitrate based tooth paste causing complete tubular occlusion (Figure $7 \& 8$ ).

\section{Conclusion}

Both toothpaste and mouthwash containing potassium nitrate effective in controlling hypersensitivity, however toothpaste having slightly better effect. More long term studies are required.

\section{References}

1. Bissada NF (1994) Symptomatology and Clinical Features of Hypersensitive Tooth. Archive of Oral Biology 39 (supplement): $31 \mathrm{~s}-32 \mathrm{~s}$.
2. Gilliam DG (1992) The assessment and treatment of cervical dentine sensitivity. [DDS Thesis]. Edinburgh, University of Edinburgh, UK.

3. Rees JS, Addy M (2004) A cross-sectional study of buccal cervical sensitivity in UK general dental practice and a summary review of prevalence studies. Int J Dent Hyg 2(2): 64-69.

4. Walters PA (2005) Dentinal hypersensitivity: A review. J Contemp Dent Pract 6(2): 107-117.

5. Chabanski MB, Gillam DG (1997) Aetiology, prevalence and clinical features of cervical dentine sensitivity. J Oral Rehabil 24(1): 15-19.

6. Braennstroem M, Astroem A (1964) A study on the mechanism of pain elicited from the dentin. J Dent Res 43: 619-625.

7. Bergenholtz G, Lindhe J (1975) Effect of soluble plaque factors on inflammatory reactions in the dental pulp. Scand J Dent Res 83(3): 153-158.

8. Yoshiyama M, Noiri Y, Ozaki K, Uchida A, Ishikawa Y, et al. (1990) Transmission electron microscopic characterization of hypersensitive human radicular dentin. J Dent Res 69(6): 1293-1297.

9. West NX (2008) Dentine hypersensitivity: Preventive and therapeutic approaches to treatment. Periodontol 2000 48: 31-41.

10. Bartold PM (2006) Dentinal hypersensitivity. Aust Dent J 51(3): 212 218.

11. Kaufman HW, Wolf MS, Winston AE, Triol CW (1999) Clinical evaluation of the effect of a remineralizing toothpaste on dentinal sensitivity. J Clin Dent 10: 50-54.

12. Dragolich WE, Pashley DH, Brennan WA, O'Neal RB, Horner JA, et al. (1993) An in vitro study of dentinal tubule occlusion by ferric oxalate. J Periodontol 64(11): 1045-1051.

13. Markowitz D, Kim S (1992) The role of selected cations in the desensitization of intradental nerves. Proc Finn Dent Soc 88(Suppl. 1): 39-54.

14. Nagata T, Ishida H, Shinohara H, Nlshikawa S, Kasahara S, et al. (1994) Clinical evaluation of a potassium nitrate dentifrice for the treatment of dentinal hypersensitivity. J Clin Periodontol 21(3): 217-221.

15. Manochehr PM, Bhat M, Bissada N (1984) Clinical evaluation of two potassium nitrate toothpastes for the treatment of dental hypersensitivity. Periodontal Case Rep 6(1): 25-30.

16. Richard Perira, Vijay Chawa (2001) Efficacy of 3\% potassium nitrate desensitizing mouthwash in treatment of Dentinal Hypersensitivity. Journal of Periodontology 72(12): 1720-1725.

17. Gillam DG, Bulman JS, Jackson RJ, Newman HN (1996) Efficacy of a potassium nitrate mouthwash in alleviating cervical dentine sensitivity (CDS). J din Periodontol 23(11): 993-997.

18. (1986) Recommendations for evaluating agents for the reduction of dentinal hypersensitivity. Ad Hoc Advisory Committee on Dentinal Hypersensitivity Council on Dental Therapeutics. J Am Dent Assoc 112(5): 709-710.

19. Erdemir U, Yildiz E, Kilic I, Yucel T, Ozel S (2010) The efficacy of three desensitizing agents used to treat dentin hypersensitivity. J Am Dent Assoc 141(3): 285-296.

20. Holland GR, Narhi MN, Addy M, Gangarosa L, Orchardson R (1997) Guidelines for the design and conduct of clinical trials on dentine hypersensitivity. J Clin Periodontol 24(11): 808-813.

21. FG Burgett, MM Ash JR (1974) Comparative Study of the Pressure of Brushing with Three Types of Toothbrushes. J Periodontal June pp. 410-413.

22. Stefan Zimmer, Öztürk M, Claudia R Barthel, Mozhgan Bizhang, Rainer A Jordan (2011) Cleaning Efficacy and Soft Tissue Trauma after use of manual Toothbrushes With Different Bristle Stiffness. J Periodontol 82(2): 267-271. 
23. Benedict Bkimmelman (1965) Teaching Two Tooth brushing Techniques: Observations and Comparisons .J Periodontol.

24. JA GIBSON (1977) Plaque Removal by the Bass and Roll Brushing Techniques. J Periodontol 48(8): 456-459.

25. Addy M, Loyn T, Adams D (1991) Dentine hypersensitivity--effects of some proprietary mouthwashes on the dentine smear layer: a SEM study. J Dent 19(3): 148-152.
This work is licensed under Creative Commons Attribution 4.0 License

DOI: 10.19080/ADOH.2018.08.555749
26. Masant Kuroiwa, Tetsuo Kodaka, T Mie Kuroiwa, Masayuki Abe (1994) Dentin Hypersensitivity. Occlusion of Dentinal Tubules by Brushing With and Without an Abrasive Dentifrice. J Periodontol 65(4): 291-296.

\section{Your next submission with Juniper Publishers will reach you the below assets}

- Quality Editorial service

- Swift Peer Review

- Reprints availability

- E-prints Service

- Manuscript Podcast for convenient understanding

- Global attainment for your research

- Manuscript accessibility in different formats ( Pdf, E-pub, Full Text, Audio)

- Unceasing customer service

Track the below URL for one-step submission https://juniperpublishers.com/online-submission.php 